\title{
Validation and Application of Model ISAREG in a Typical Semiarid Sand-Meadow Area of Horqin Sandy Land*
}

\author{
Yao Wu ${ }^{1}$, Tingxi Liu ${ }^{1}$, Luis Pereira ${ }^{2}$, Paula Perards ${ }^{2}$, and Haiyan Wang ${ }^{1}$ \\ ${ }^{1}$ College of Conservancy and Civil Engineering, \\ Inner Mongolia Agricultural University, Hohhot 010018, China \\ ${ }^{2}$ Agricultural Engineering Research Centre, Institute of Agronomy, \\ Technical University of Lisbon, Portugal \\ \{wuyao.will, txliu1966\}@163.com
}

\begin{abstract}
Win ISAREG is a model for performing soil water balance and estimating impacts of water stress on yields for crops, concentrating on the evaluation of irrigation scheduling. The soil water balance of different type of soil and crop were study in the typical semiarid Horqin Sandy land area in this paper. With the data from Agula experimental station and concentrate on site A3 with Artemisia and site D1 with leymus, the calibration and validation for both sites were performed by using field observations of 2008 and 2009, aiming to adjust the crop coefficients $\mathrm{Kc}$ and soil water depletion fractions for nonstress conditions $p$ to the local conditions. Results show that the coefficients of regression was close to 1.0 , the relative errors to estimate the soil water content was 0.09 for Artemisia and 0.10 for leymus. Results prove the practicality and applicability of using ISAREG for the Horqin semiarid area.
\end{abstract}

Keywords: Model ISAREG, Horqin sandy land, simulation, validation, soil moisture.

\section{Introduction}

Desertification area in China mainly distributes in north and northwest, which has complex and diverse geographical ecosystem. Special position and geomorphic features result in significant differences for hydrological process between the north and south desertification area (2005). The ecosystem in North China including sandy land, desert and agricultural land, specially for the meadow and sandy dunes take shape of stripe distribution, forming meadow- transition area- sandy dunes multi-

\footnotetext{
* National Natural Science Foundation of China, No. 51139002; No.51069005; Inner Mongolia Agricultural University innovation Team Building Program Cold-Arid Region Water Resources Utilization, No. NDTD2010-6; Inner Mongolia Scientific and Technology Bureau No. 20090516; Project of the Ministry of Science and Technology of China, No. 2010DFA71460.
} 
cascade ecological system. Soil water evaporation plant transpiration are the most important parts in soil water balance, the soil water evaporation reduced soil water content, crops has influent by water stress under arid condition. Concerns have been focus on the study of eco-hydrological process in arid and semiarid region (Yang, 2006).

\section{Materials and Method}

\subsection{Experimental Station}

The $9.71 \mathrm{~km} 2$ study area is located in the south of Horqin sandy land (Fig 1), Horqin sandy land is $51700 \mathrm{~km}^{2}$ and it's situated between the Inner Mongolian Plateau and the Northeast China Plain. The area has an elevation ranging from $88.5 \mathrm{~m}$ to $308.4 \mathrm{~m}$ above mean sea level (Duan, 2011). The study area was chosen because it's located in the typical desertification area -- the Horqin Sandy area(Fig.1), with the dune-cascade transition zone-meadow geomorphic feature making up the unique ecosystem, which contains $54.5 \%$ sand dunes, $26.6 \%$ meadow lands, $10.4 \%$ cultivation area and $5.2 \%$ lake area (Duan 2011). Lots of observations have been done in this area from year of 2004 to support research on eco-hydrological system.
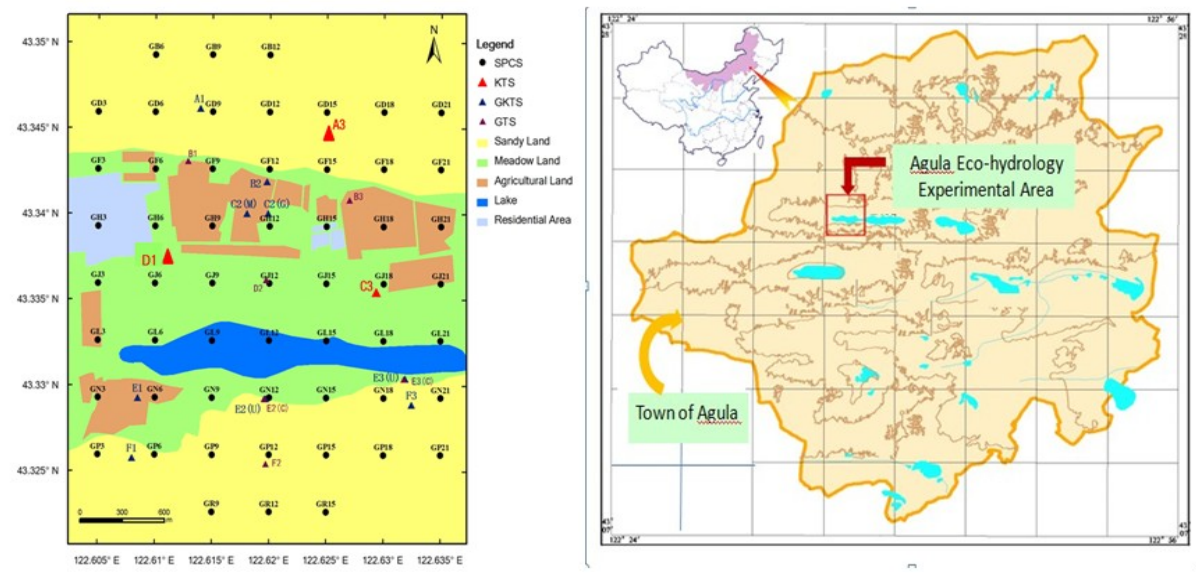

Fig. 1. The location and landscape features of the study area, soil physicochemical sites and hydrologic and meteorological stations

Table 1. Characteristics of the measurement sites for A3 and D1

\begin{tabular}{lccll}
\hline Site NO. & Land Feature & Soil Texture & Type of Vegetation & Elevation \\
\hline A3 & Mobile dune & Sand & Artemisia halodendron & 199.8 \\
D1 & Meadow & Sandy loam & Leymus chinensis & 188.5 \\
\hline
\end{tabular}


The study area has a temperate continental monsoon climate, with the average annual precipitation vary from $350 \mathrm{~mm}$ to $550 \mathrm{~mm}$ over the period of year 1957 to $2009,70 \%$ of which is concentrated from June to August., with the average annual evaporation between $1700 \mathrm{~mm}$ to $2000 \mathrm{~mm}$. Temperature goes along with the seasonal trend, with the average annual value is $5.8^{\circ} \mathrm{C}$, and the minimum in January $\left(-15.1^{\circ} \mathrm{C}\right)$ and maximum in July $\left(23.8^{\circ} \mathrm{C}\right.$ ) (Wang 2008). The relative humidity varying from $50 \%$ to $60 \%$, which has the lower value in summer and higher value in winter. The average annual wind speed in the area In the study area, it has mobile dune, fixed dune, semifixed dune that correspond with sand, sandy loam as the texture in the sandy sites, and the meadow sites with the sandy loam. The distribution of vegetation follows the zonality of landform. The sandy dunes are covered mainly by Artemisia halodendron L., Salix gordejevii Chang\& Skvortsov, and Populus, the type of natural vegetation on meadow sites are Leymus chinensis Tzvelev, Phragmites australis Trin., and/or Ixeris chinensis Nakai.

Table 2. Soil characteristic of the site A3 and D1

\begin{tabular}{rcccc}
\hline $\begin{array}{l}\text { Site } \\
\text { NO. }\end{array}$ & $\begin{array}{c}\text { Depth } \\
(\mathbf{m})\end{array}$ & $\begin{array}{c}\text { Bulk density } \\
\left(\mathbf{g} / \mathbf{c m}^{\mathbf{3}}\right)\end{array}$ & $\begin{array}{c}\text { Field capacity } \\
(\boldsymbol{\%} \text { volume })\end{array}$ & $\begin{array}{c}\text { Wilting point } \\
(\boldsymbol{\%} \text { volume })\end{array}$ \\
\hline \multirow{3}{*}{ D1 } & $0.00-0.10$ & 1.70 & 0.26 & 0.10 \\
& $0.10-0.40$ & 1.66 & 0.28 & 0.09 \\
& $0.40-1.00$ & 1.57 & 0.38 & 0.23 \\
& $0.00-0.80$ & 1.52 & 0.18 & 0.04 \\
A3 & $0.80-1.60$ & 1.57 & 0.17 & 0.03 \\
& $1.60-2.20$ & 1.55 & 0.20 & 0.03 \\
\hline
\end{tabular}

\subsection{Instrumentation and Data Collection}

The Agula eco-hydrological experimental station has been established since 2003, 16 sites has been chosen for typical points, including two key typical sites ( KTS) and ten general key sites(GKTS) and four groundwater observed sites( GTS). Continuous observation has been taken of all 16 sites since 2004. Measurements are shown as below:

a. The soil physical and chemical characteristic parameters in the top $30 \mathrm{~cm}$ layer, including soil water content for every layer, soil classification, soil bulk density, the electric conductive(EC), soil $\mathrm{pH}$ value, soil organic content;

b. the groundwater depth of the 16 sites;

c. automatic meteorological station and monitoring of environmental gradient were set on the sites of A3 and C3(Fig .1), measurements including wind speed, humidity, temperature, of $2 \mathrm{~m}, 3 \mathrm{~m}$ and $10 \mathrm{~m}$, the soil water content, soil temperature and soil salinity of every soil layer. Also total radiation, photosynthetically active radiation, sunlight hour, rainfall. 
d. The soil water content measured by the time domain reflectometer (TDR) and neutron probe.

e. The crop information about the crop height, root depth, and development stages.

The characteristic of the soil for sites have been chosen for simulation showed in Table. 1 and Table. 2.

\subsection{Model ISAREG}

The Win ISAREG model was used to performing simulations of soil water balance, which is the integration of two different models, the EVAP56-for computing reference evapotranspiration, and the ISAREG part as to describe(2003, Pereira et al). The model and its calibration and validation for Portuguese conditions were presented by Teixeira and Pereira (1992).

Input data for the model ISAREG

(1) Meteorological data: precipitation, $\mathrm{Pe}(\mathrm{mm})$, wind speed $(\mathrm{m} / \mathrm{s})$ and minimum relative humidity, RHmin(\%), the calculation module EVA56 following the FAO-Penman Monteith method was used for computing ETo (Allen et al,1994).

(2) Crop data: including the dates of crop growth stages and crop coefficients Kc, soil water depletion fractions for non-stress conditions $\mathrm{p}$, root depth $\mathrm{Zr}(\mathrm{m})$. the information of the sites A3 and D1 has been shown in Table 3.

(3) Soil data: according to the soil profile the respective depth for each soil layer, $\mathrm{d}(\mathrm{m})$, and the soil water characteristic parameters as field capacity and wilting point for computing the total evaporable water( TEW) and Readily evaporable water (REW).

(4) Irrigation characteristic data: for the case there is no irrigation during the crop growth stages, concentrating on the Groundwater Contribution data, according to the proposed value by Liu (Liu, 2006) to choose parameters, input the water table depth of the chosen days as well.

Table 3. Crop information from field experiments utilized in the model simulation for Artemisia and Leymus

\begin{tabular}{|c|c|c|c|c|c|}
\hline \multirow{2}{*}{\multicolumn{2}{|c|}{ Crop Stages }} & \multicolumn{2}{|c|}{ Artemisia } & \multirow[b]{2}{*}{ Date } & \multirow{2}{*}{$\begin{array}{c}\text { Leymus } \\
\text { Root depth(m) }\end{array}$} \\
\hline & & Date & Root depth(m) & & \\
\hline stage A & Initial period & $5 / 1$ & 1.0 & $5 / 5$ & 0.5 \\
\hline Stage B & $\begin{array}{l}\text { Start of vegetative } \\
\text { growth }\end{array}$ & $5 / 15$ & 1.0 & $5 / 20$ & 0.5 \\
\hline Stage C & Full cover & $6 / 10$ & 1.1 & $6 / 15$ & 0.5 \\
\hline Stage $\mathbf{E}$ & Ripening & $10 / 1$ & 1.1 & $10 / 01$ & 0.5 \\
\hline Stage $\mathbf{F}$ & End season & $11 / 1$ & 1.1 & $11 / 1$ & 0.5 \\
\hline
\end{tabular}


Site A3

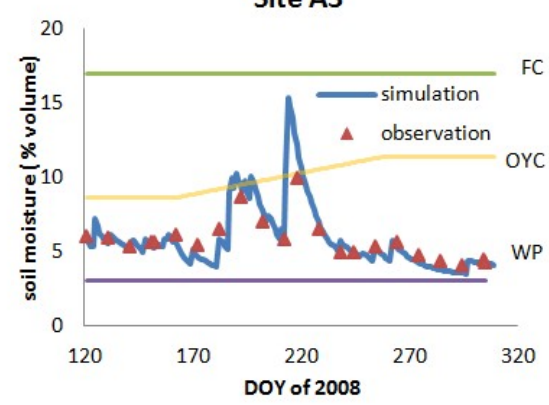

Site D1

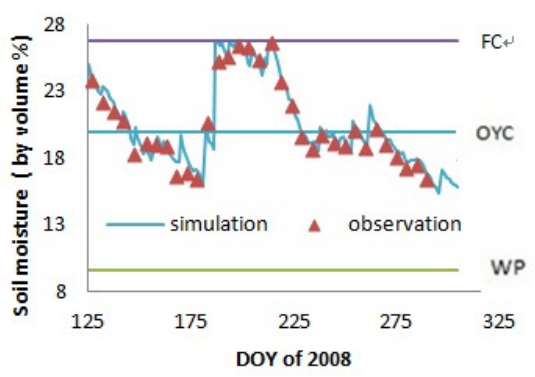

Site A3

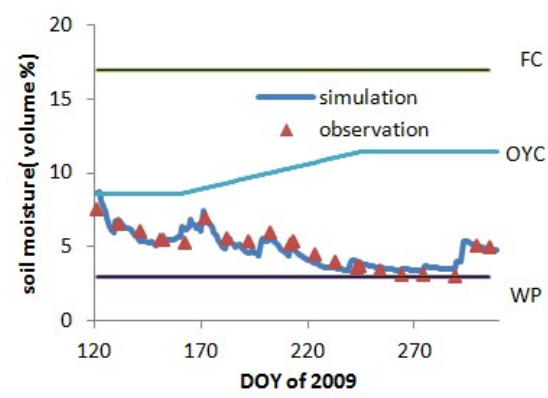

Site D1

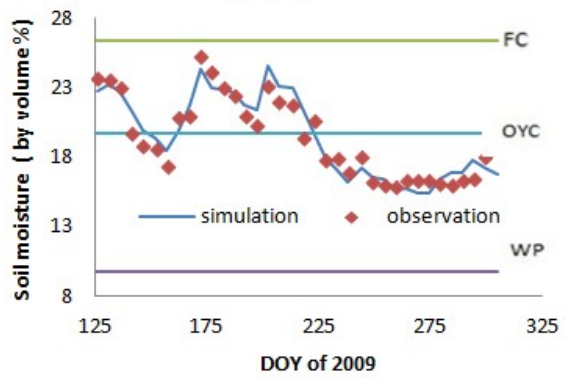

Fig. 2. Observed and simulated. soil moisture for site A3(Artemisia) and D1 ( Leymus ) of year 2008 and 2009 curves $F \mathrm{c}$ and $W \mathrm{p}$ represent soil moisture at field capacity and at wilting point

- The root mean square error (same units as $\mathrm{O}_{\mathrm{i}}$ ), which characterizes the variance of the errors.

$$
\operatorname{RMSE}=\left(\frac{\sum_{\mathrm{i}=1}^{\mathrm{n}}\left(\mathrm{P}_{\mathrm{i}}-\mathrm{O}_{\mathrm{i}}\right)^{2}}{\mathrm{n}}\right)^{0.5}
$$

- The average absolute error (same units as $\mathrm{O}_{\mathrm{i}}$ ), which expresses the size of estimation errors in alternative to RMSE.

$$
A A E=\frac{1}{\mathrm{n}} \sum_{i=1}^{n}\left|O_{i}-P_{\mathrm{i}}\right|
$$


- The average relative error (\%) that indicates the size of errors in relative terms.

$$
A A E=\frac{100}{\mathrm{n}} \sum_{i=1}^{n}\left|\frac{O_{i}-P_{i}}{O_{i}}\right|
$$
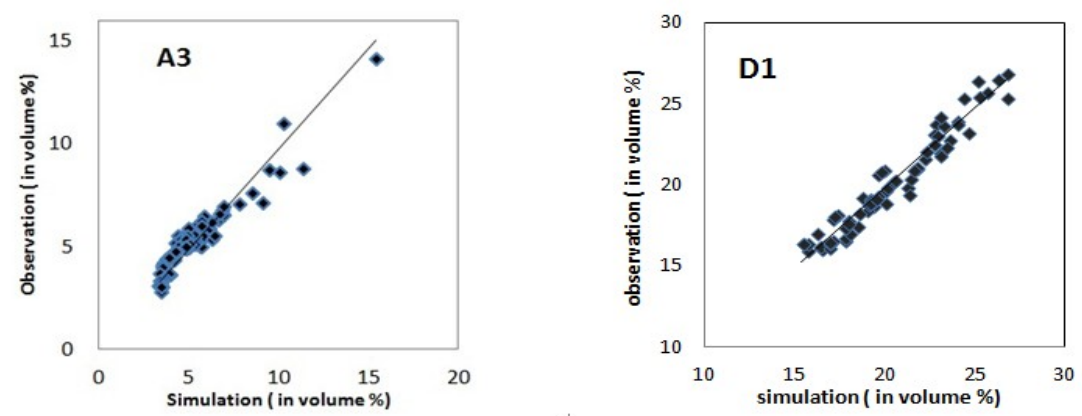

Fig. 3. Soil moisture simulated with the model Win ISAREG and observed at Agula eco-hydrology experimental station. Site A3 and Site D1

\section{$3 \quad$ Results and Discussion}

Calibration and validation of model for soil moisture, model ISAREG calibrated using 2008 data collected from Agula experimental sites, the crop coefficients Kc and soil water depletion fraction $\mathrm{p}$ were adjusted for both two sites A3 and D1, the simulation of soil moisture along the development periods were compared with the observation( Fig 2 ). Seasonal changes of the soil moisture of simulations comparing with observations were shown (Fig. 2 and Fig. 3 ) for sandy site A3 with Artemisia and meadow site D1 with leymus relative to 2008 and 2009. The calibrated crop parameters Kc and p are presented in Table 4.

The first value of $\mathrm{Kc}_{\text {ini }}$ of $\mathrm{A} 3(0.5)$ and $\mathrm{D} 1$ (0.3)was taken from Allen et al(1998)and then adjust for the actual condition., as for Artemisia there is no irrigation during the whole period, during the initial period, evapotranspiration mainly come from soil evaporation, as the low frequency of rainfall, $\mathrm{Kc}_{\mathrm{ini}}$ is low. For the site $\mathrm{D} 1$, leymus starts to grow quickly, Kc-0.3, which obtained in the model was the same as to the 0.30 suggested by Allen et al (1998). The midseason for Artemisia is obtained as 1.10 , when the leymus is lower as 0.9 , and between the value $(0.85-1.05)$ proposed by Allen et al (1998). This is explained by the soil characteristic and the relative humidity, site D1 is close to the lake, with higher humidity. 
$\mathrm{Kc}_{\text {end }}$ was adjusted as 0.5 for leymus site and 0.4 for Artemisia site, water supply was applied only for small amount of rainfall during the last season, due to the dry soil surface, the value was lower than proposed in FAO.

The soil water depletion fractions for non-stress conditions $p$ is relative to the climate, as the desiccation result in higher Etc, $\mathrm{p}$ for both sites was adopted as 0.5 (A3) and 0.6( D1), which are lower than value in the FAO table (Allen et al, 1998). The initial value for $p$ used in this study was taken from the guideline of FAO (Allen et al., 1998). Because of the condition of semiarid area, with the high frequency of strong wind, the $\mathrm{Kc}_{\text {mid }}$ should be higher, but as the crop wasn't seed ordered but natural growth, especially for A3 the smaller surface coverage.

The coefficients of regression through the origin, $\mathrm{b}$ is very close to 1 , when the coefficient of determination $\mathrm{R}^{2}$, for both $\mathrm{D} 1$ and $\mathrm{A} 3$ are acceptable (Table. 4).

The root mean square error(RMSE) for calibration and validation is 0.006 and 0.004 of site A3, and 0.008 and 0.010 of site D1,which indicate that the estimation errors are small.

The average of absolute errors (AAE) of soil moisture is low, less than $1 \%$ in volume (Table 4). Results show that the AAE is acceptable for prediction.

The average relative error of estimates, ARE (Table 4) confirm the analysis above,for A3, it is 9.10 and 8.90, not exceeding 10\%, for D1 it's 2.88 and 4.42, lower errors are expected. Results showed that the model is appropriate for this area.

Table 4. Quality of model simulation of soil moisture for data sets utilized to calibration and validation

\begin{tabular}{ccccccc}
\hline Parameters & Site NO. & $\begin{array}{c}\text { Regression } \\
\text { coefficient } \\
\mathbf{b}\end{array}$ & $\begin{array}{c}\text { determination } \\
\text { coefficient } \\
\mathbf{R}^{\mathbf{2}}\end{array}$ & $\begin{array}{c}\mathbf{R M S E} \\
\left(\mathbf{m}^{\mathbf{3}} / \mathbf{m}^{\mathbf{3}}\right)\end{array}$ & $\begin{array}{c}\mathbf{A A E} \\
\left(\mathbf{m}^{\mathbf{3}} / \mathbf{m}^{\mathbf{3}}\right)\end{array}$ & ARE(\%) \\
\hline \multirow{2}{*}{ Model calibration } & A3 & 0.98 & 0.96 & 0.006 & 0.005 & 9.10 \\
& D1 & 0.98 & 0.91 & 0.008 & 0.006 & 2.88 \\
Model validation & A3 & 1.00 & 0.89 & 0.004 & 0.004 & 8.90 \\
& D1 & 0.99 & 0.89 & 0.010 & 0.009 & 4.42 \\
\hline
\end{tabular}

\section{Conclusions}

This study is based on collecting data from the typical semiarid area- Agula ecohydrological experimental station. Calibration and validation for Model ISAREG was performed using soil water content observations. By using continuous observations data of 2008 and 2009 comparing with simulations using ISAREG, calibration and validation for crop parameter $\mathrm{K}_{\mathrm{c}}$ was analysis, results showed the Model ISAREG has accurately simulated the variability of soil water content of Artemisia for sandy dunes and Leymus for meadow area. Also with Model ISAREG, the $\mathrm{K}_{\mathrm{c}}$ has been estimated for both Artemisia and Leymus of different development stages in the semiarid area. 
The $\mathrm{Kc}_{\text {ini }}, \mathrm{Kc}_{\text {mid }}$ and $\mathrm{Kc}_{\text {end }}$ for Artemisia are 0.50, 1.10 and 0.60, for Leymus it's 0.30, 0.90 and 0.50 . It can be concluded that the model for prediction in this area is available and acceptable.

Acknowledgements. This study was financially supported by the National Natural Science Foundation of China under contract \#51069005, and Inner Mongolia Scientific and Technology Bureau under contract \#20090516. With my sincere thanks to Professor Tingxi Liu, Prof. Luis Pereira, Paula Perareds and colleagues in IMAU and CEER for supporting and guidance. Special thanks to the people Dakang Liu, Guanli Wang, limin Duan, who made the contribution for establishment of the experimental station and collected data.

\section{References}

Allen, R.G., Smith, M., Pereira, L.S., Perrier, A.: An update for the calculation of the reference evapotranspiration. ICID Bull. 43(2), 35-92 (1994)

Allen, R.G., Smith, M., Pruitt, W.O., Pereira, L.S.: Modifications to the FAO crop coefficient approach. In: Camp, C.R., Sadler, E.J., Yoder, R.E. (eds.) Proc. Int. Conf. on Evapotranspiration and Irrigation Scheduling, San Antonio, pp. 124-132. ASAE, St. Joseph (1996)

Allen, R.G., Pereira, L.S., Raes, D., Smith, M.: Crop Evapotranspiration. Guidelines for Computing Crop Water Requirements. Irrigation and Drainage Paper 56. FAO, Rome (1998)

Liu, Y., Teixeira, J.L., Zhang, H.J., Pereira, L.S.: Model validation and crop coefficients for irrigation scheduling in the North China Plain. Agric. Water Manage. 36, 233-246 (1998)

Liu, Y., Pereira, L.S., Fernando, R.M.: Fluxes through the bottom boundary of the root zone in silty soils: Parametric approaches to estimate groundwater contribution and percolation. Agric. Water Manage. 84, 27-40 (2006)

Teixeira, J.L., Pereira, L.S.: ISAREG, an irrigation scheduling simulation model. ICID Bull. 41(2), 29-48 (1992)

Pereira, L.S., van den Broek, B., Kabat, P., Allen, R.G. (eds.): Crop-Water Simulation Models in Practice, p. 332. Wageningen Press, Wageningen (1995)

Chen, F., Cai, H., Wang, J., et al.: Estimation of evapotranspiration and crop coefficients of winter wheat and summer maize in Yangling zone. Transactions of the Chinese Society of Agriculture Engineering 22(5), 191-193 (2006) (in Chinese with English abstract)

Liu, Y., Pereira, L.S.: Validation of FAO methods for estimating crop coefficients. Transactions of the Chinese Society of Agriculture Engineering 16(5), 26-30 (2000) (in Chinese with English abstract)

Doorenbos, J., Pruitt, W.O.: Guidelines for Predicting Crop Water Requirements. Irrigation and Drainage Paper 24, Food and Agriculture Organization of the United Nations, Rome, Italy (1997) 
Wang, G.: Simulation analysis for water transforming based on field test for GSPAC system in dune-meadow-dune area in Horqin Sand, Ph. D. thesis, Inner Mongolia Agricultural University, 117 p. (2008)

Duan, L., Liu, T., Wang, X., et al.: Spatio-temporal variations in soil moisture and physicochemical properties of a typical semiarid sand-meadow-desert landscape as influenced by land use. Hydrol. Earth Syst. Sci. 15, 1865-1877 (2011) 